Cite this: J. Mater. Chem. A, 2014, 2, 10435

Received 14th March 2014

Accepted 27th April 2014

DOI: $10.1039 / c 4 t a 01272 k$

www.rsc.org/MaterialsA

\section{A transformative route to nanoporous manganese oxides of controlled oxidation states with identical textural properties $\uparrow$}

\begin{abstract}
Jae Hwa Lee, $\ddagger^{a}$ Young Jin Sa, $\ddagger^{a}$ Tae Kyung Kim, ${ }^{a}$ Hoi Ri Moon*a and Sang Hoon Joo*b
Nanoporous nanocrystalline metal oxides with tunable oxidation states are crucial for controlling their catalytic, electronic, and optical properties. However, previous approaches to modulate oxidation states in nanoporous metal oxides commonly lead to the breakdown of the nanoporous structure as well as involve concomitant changes in their morphology, pore size, surface area, and nanocrystalline size. Herein, we present a transformative route to nanoporous metal oxides with various oxidation states using manganese oxides as model systems. Thermal conversion of $\mathrm{Mn}$-based metal-organic frameworks (Mn-MOFs) at controlled temperature and atmosphere yielded a series of nanoporous manganese oxides with continuously tuned oxidation states: $\mathrm{MnO}, \mathrm{Mn}_{3} \mathrm{O}_{4}, \mathrm{Mn}_{5} \mathrm{O}_{8}$, and $\mathrm{Mn}_{2} \mathrm{O}_{3}$. This transformation enabled the preparation of low-oxidation phase $\mathrm{MnO}$ and metastable intermediate phase $\mathrm{Mn}_{5} \mathrm{O}_{8}$ with nanoporous architectures, which were previously rarely accessible. Significantly, nanoporous $\mathrm{MnO}$, $\mathrm{Mn}_{3} \mathrm{O}_{4}$, and $\mathrm{Mn}_{5} \mathrm{O}_{8}$ had a very similar morphology, surface area, and crystalline size. We investigated the electrocatalytic activity of nanoporous manganese oxides for oxygen reduction reaction (ORR) to identify the role of oxidation states, and observed oxidation state-dependent activity and kinetics for the ORR.
\end{abstract}

\section{Introduction}

Nanoporous metal oxide materials with crystalline frameworks have been of prime importance in various fields, including adsorption, catalysis, and energy conversion and storage. ${ }^{1-5}$ In these materials, the control of oxidation states is crucial for tailoring their catalytic, electronic, and optical properties. Over the last two decades, diverse soft and hard templating strategies have been developed to prepare nanoporous metal oxides with a rich variety of compositions and structures. ${ }^{6-14}$ However, these methods usually involve solution processes and subsequent high-temperature annealing steps, which have limited the range of stable metal oxide phases predominantly to those with

${ }^{a}$ Department of Chemistry, Ulsan National Institute of Science and Technology (UNIST), 50 UNIST-gil, Ulsan 689-798, Republic of Korea. E-mail: hoirimoon@unist. $a c . k r$

${ }^{b}$ School of Energy and Chemical Engineering and KIER-UNIST Advanced Center for Energy, Ulsan National Institute of Science and Technology (UNIST), 50 UNIST-gil, Ulsan 689-798, Republic of Korea. E-mail: shjoo@unist.ac.kr; Fax: +82-52-217-2509; Tel: $+82-52-217-2522$

$\dagger$ Electronic supplementary information (ESI) available: X-ray crystallographic data, XRPD pattern and TGA data for Mn-MOF, the pore size distribution of the nanoporous $\mathrm{MnO}, \mathrm{Mn}_{3} \mathrm{O}_{4}$, and $\mathrm{Mn}_{5} \mathrm{O}_{8}$, characterization data for $\mathrm{Mn}_{2} \mathrm{O}_{3}$, LSV polarization curves of the nanoporous manganese oxides at different rotating speeds, Nyquist plots of the nanoporous manganese oxides, and LSV polarization curves of the nanoporous manganese oxides including MnO. CCDC 978436. For ESI and crystallographic data in CIF or other electronic format see DOI: $10.1039 / \mathrm{c} 4 \mathrm{ta} 01272 \mathrm{k}$

\$ These authors contributed equally to this work. high oxidation numbers. In addition, post-synthetic thermal treatments aimed at changing the oxidation states of nanoporous metal oxides often result in the growth of nanocrystalline domain size, which consequently leads to the breakdown of the nanoporous structure. Hence, the preparation of nanoporous metal oxides with broadly tunable oxidation states, particularly those with low oxidation or metastable intermediate phases, has been challenging.

Recently, conversion reactions that transform pre-synthesized nanoscale or microscale inorganic solid precursors into new materials have emerged as new synthetic toolboxes in materials chemistry. ${ }^{15-19}$ Conversion reactions have been explored extensively with various types of precursors, and have enabled the synthesis of new materials with a high degree of compositional and structural complexity. The versatility of conversion reactions can be exemplified in the preparation of thermodynamically unfavorable hollow nanoparticles from solid analogues by exploiting the nanoscale Kirkendall effect ${ }^{20}$ or galvanic replacement reaction. ${ }^{21}$ In the context of conversion reactions, metal-organic frameworks (MOFs), in which inorganic and organic building blocks are alternatively arranged in a periodic manner, can serve as excellent precursors, and accordingly, conversion reactions utilizing MOFs are currently being actively pursued..$^{22-31}$ In this line of effort, we recently reported the preparation of nanoporous non-siliceous metal oxides with nanocrystalline frameworks via thermal conversion of MOFs for the first time. ${ }^{30}$ 
Herein, we demonstrate that conversion reactions using MOFs as precursors can be successfully exploited to prepare nanoporous nanocrystalline metal oxides with tunable oxidation states. Manganese oxides were chosen as a model system because they can exist in various oxidation states ${ }^{32}$ and are the centers of great interest in energy conversion and storage as well as catalysis. ${ }^{33-36}$ We show that sequential conversion reactions are capable of transforming a Mn-based MOF (Mn-MOF) into nanoporous nanocrystalline manganese oxides with continuously tuned oxidation states, $\mathrm{MnO}, \mathrm{Mn}_{3} \mathrm{O}_{4}, \mathrm{Mn}_{5} \mathrm{O}_{8}$, and $\mathrm{Mn}_{2} \mathrm{O}_{3}$, with conservation of the original morphology of the Mn-MOF crystals (Fig. 1). Importantly, these conversion reactions enabled the preparation of low-oxidation-state $\mathrm{MnO}$ and metastable intermediate $\mathrm{Mn}_{5} \mathrm{O}_{8}$ phases with nanoporous nanocrystalline architecture, which was previously difficult to access. Nanoporous $\mathrm{MnO}, \mathrm{Mn}_{3} \mathrm{O}_{4}$, and $\mathrm{Mn}_{5} \mathrm{O}_{8}$ have almost identical textural properties, including their morphology, surface areas, pore volumes, and the size of nanocrystals composing nanoporous frameworks. The textural similarity among the series of manganese oxides allowed them to be used as a system for studying the oxidation-state effect in catalysis; previous studies related to such an effect were mostly performed with a series of catalysts possessing various other variables that can affect catalytic performances..$^{37-40}$ We investigated the electrocatalytic activity of these nanoporous manganese oxides for the oxygen reduction reaction (ORR), and observed oxidation-state-dependent catalytic activity and kinetics in the ORR.

\section{Experimental section}

\subsection{Materials}

All chemicals and solvents were of reagent grade and used without further purification. meso-Butane-1,2,3,4-tetracarboxylic acid $\left(\mathrm{H}_{4} \mathrm{BuTC},>98 \%\right)$ and $N, N$-dimethylacetamide (DMA, $>99 \%)$ were supplied by TCI. $\mathrm{Mn}\left(\mathrm{NO}_{3}\right)_{2} \cdot 4 \mathrm{H}_{2} \mathrm{O}(>97 \%)$ was purchased from Aldrich.

\subsection{Synthesis of Mn-MOF ([Mn $\left.\left.2(B u T C)(D M A)_{2}\right]_{n}\right)$}

$\mathrm{H}_{4}$ BuTC (0.037 g, $\left.0.16 \mathrm{mmol}\right)$ was dissolved in DMA $(2.5 \mathrm{~mL})$ and mixed with a DMA $(2.5 \mathrm{~mL})$ solution of $\mathrm{Mn}\left(\mathrm{NO}_{3}\right)_{2} \cdot 4 \mathrm{H}_{2} \mathrm{O}$ $(0.080 \mathrm{~g}, 0.32 \mathrm{mmol})$. The solution was sealed in a glass jar, heated to $100{ }^{\circ} \mathrm{C}$ for $24 \mathrm{~h}$, and then cooled to room temperature. Yellowish leaf-shaped crystals formed, which were filtered and washed briefly with the mother liquor. Yield: 35\%. FT-IR (Nujol mull): $\nu_{\mathrm{C}=\mathrm{O}}(\mathrm{DMA}), 1652$ (s); $\nu_{\mathrm{O}-\mathrm{C}=\mathrm{O}}, 1615,1418$ (s) $\mathrm{cm}^{-1}$. Anal. calcd for $\mathrm{Mn}_{2} \mathrm{C}_{16} \mathrm{H}_{24} \mathrm{O}_{10} \mathrm{~N}_{2}$ : C, 37.37; H, 4.70; N, 5.45. Found: C, 37.53 ; H, 4.59; N, 5.44\%.

\subsection{Conversion reactions of Mn-MOFs into manganese oxides}

MnO. Solid Mn-MOF was heated at $5{ }^{\circ} \mathrm{C} \min ^{-1}$ under a

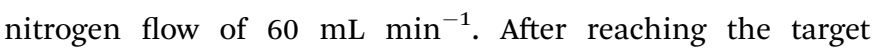
temperature of $550{ }^{\circ} \mathrm{C}$, the material was maintained at that temperature for $12 \mathrm{~h}$. After cooling to room temperature, black solid was obtained.
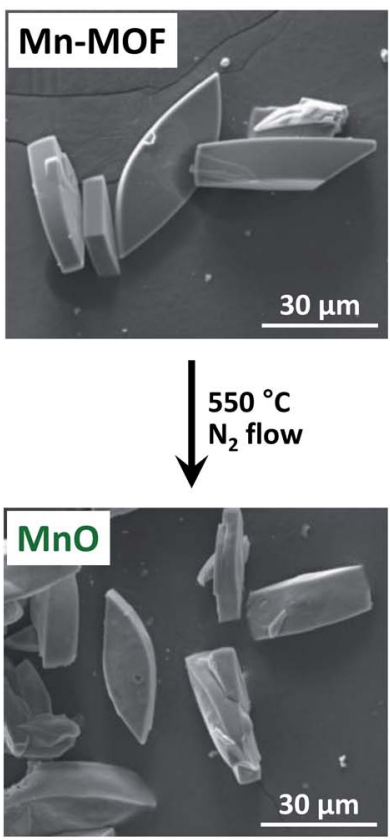
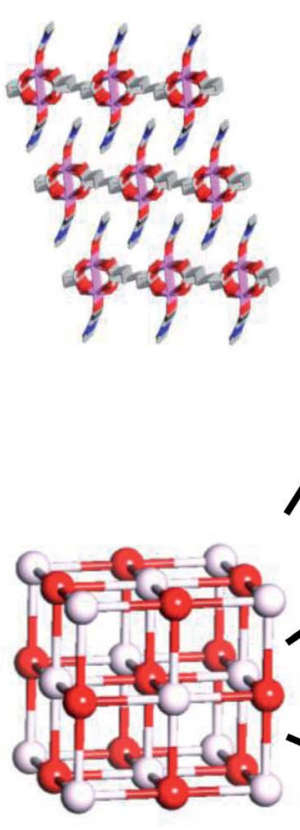
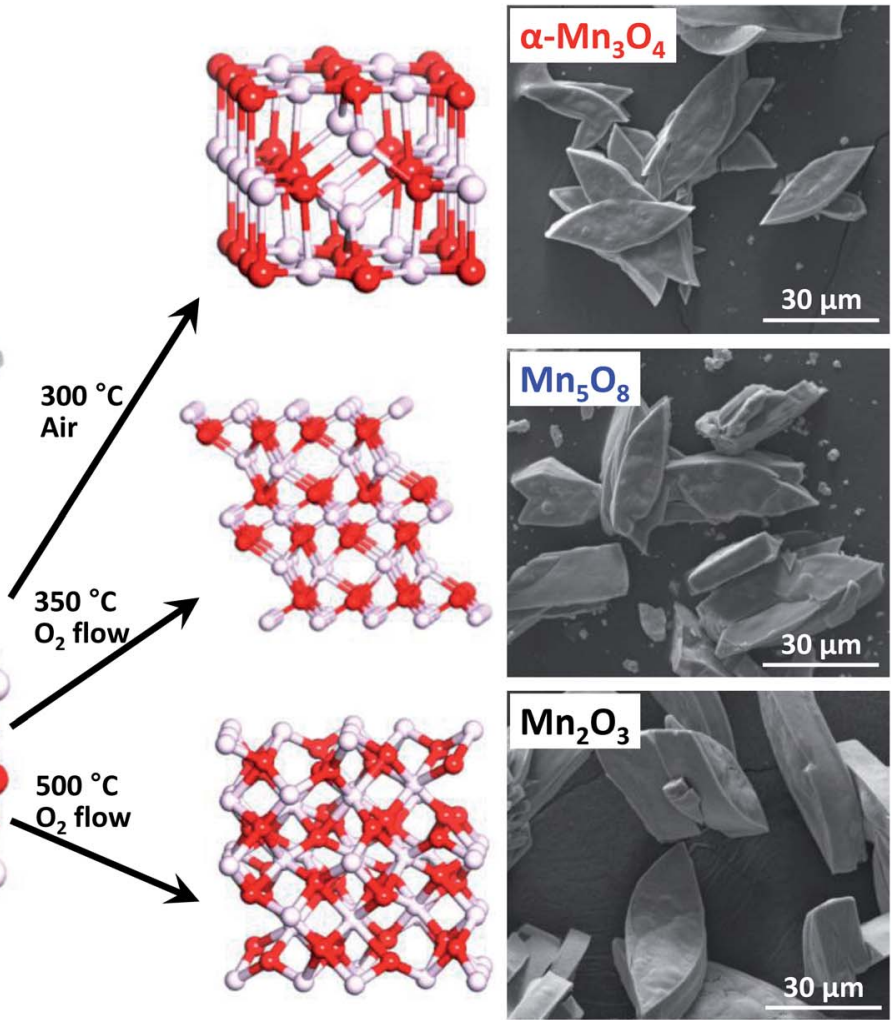

Fig. 1 SEM images and atomic structures of $\mathrm{Mn}-\mathrm{MOF}$ and converted manganese oxides during structural transformation of $\mathrm{Mn}-\mathrm{MOF}$ into $\mathrm{MnO}$, $\mathrm{Mn}_{3} \mathrm{O}_{4}, \mathrm{Mn}_{5} \mathrm{O}_{8}$ and $\mathrm{Mn}_{2} \mathrm{O}_{3}$. 
$\mathbf{M n}_{3} \mathbf{O}_{4}$. As-synthesized $\mathrm{MnO}$ solid was heated in a box furnace (ambient air environment) at $5{ }^{\circ} \mathrm{C} \mathrm{min}{ }^{-1}$. After reaching the target temperature of $300{ }^{\circ} \mathrm{C}$, the material was maintained at that temperature for $2 \mathrm{~h}$. After cooling to room temperature, brownish solid was obtained.

$\mathbf{M n}_{5} \mathbf{O}_{8}$. As-synthesized $\mathrm{MnO}$ solid was heated at $1{ }^{\circ} \mathrm{C} \mathrm{min}^{-1}$

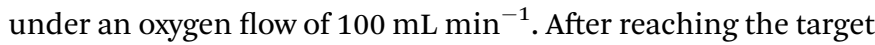
temperature of $350{ }^{\circ} \mathrm{C}$, the material was maintained at that temperature for $2 \mathrm{~h}$. After cooling to room temperature, blackish solid was obtained.

$\mathbf{M n}_{2} \mathbf{O}_{3}$. As-synthesized $\mathrm{MnO}$ was heated at $1{ }^{\circ} \mathrm{C} \min ^{-1}$ under

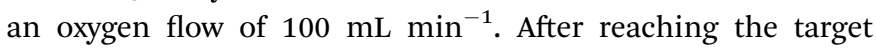
temperature of $500{ }^{\circ} \mathrm{C}$, the material was maintained at that temperature for $2 \mathrm{~h}$. After cooling to room temperature, dark grey powder was obtained.

\subsection{Single-crystal $X$-ray crystallography}

A single-crystal of Mn-MOF was coated with paratone- $N$ oil, and the diffraction data were obtained at $100 \mathrm{~K}$ with synchrotron radiation $(\lambda=0.69999 \AA)$ on an ADSC Quantum-210 detector at 2D SMC with a silicon (111) double crystal monochromator (DCM) at the Pohang Accelerator Laboratory, Republic of Korea. The ADSC Q210 ADX program ${ }^{41}$ was used for data collection, and HKL3000sm (Ver. 703r) ${ }^{42}$ was used for cell refinement, reduction, and absorption correction. The crystal structures were solved by direct methods and refined by full-matrix leastsquares calculations with the SHELX-97 computer program. ${ }^{43}$ The positions of all non-hydrogen atoms were refined with anisotropic displacement factors. The hydrogen atoms were positioned geometrically using a riding model.

\subsection{Characterization methods}

All characterization processes were carried out at the Ulsan National Institute of Science and Technology (UNIST) Central Research Facilities (UCRF) Center. Infrared spectra were recorded with a Thermo Fisher Scientific iS10 FT-IR spectrometer. Elemental analyses (for C, H, N, S, and O) were performed by using a Thermo Scientific Flash 2000 series CHNS/O analyzer. Thermogravimetric analyses (TGA) were performed under nitrogen gas at a scan rate of $5{ }^{\circ} \mathrm{C} \mathrm{min}^{-1}$, using a TGA Q50 from TA Instruments. X-ray photoelectron spectroscopy (XPS) was performed on a K-alpha from Thermo Fisher. X-ray powder diffraction (XRPD) data were recorded on a Bruker D8 advance diffractometer at $40 \mathrm{kV}$ and $40 \mathrm{~mA}$ and a Bruker D2 phaser diffractometer at $30 \mathrm{kV}$ and $10 \mathrm{~mA}$ using $\mathrm{Cu} \mathrm{K} \alpha(\lambda=1.541 \AA)$ radiation, with a step size of $0.02^{\circ}$ in $2 \theta$. Scanning electron microscope (SEM) images were taken using a Quanta 200 microscope (FEI) operating at $18 \mathrm{kV}$. Transmission electron microscope (TEM) images and energy dispersive X-ray spectra were obtained with a JEOL JEM-2100F microscope. The nitrogen adsorption-desorption isotherms were measured at $-196{ }^{\circ} \mathrm{C}$ using liquid nitrogen on a BELSORP-MAX. Prior to the adsorption measurement, the samples were evacuated at $200{ }^{\circ} \mathrm{C}$ under vacuum ( $p<10^{-5}$ mbar) overnight. The specific surface area was determined in the relative pressure range from 0.05 to 0.3 of the Brunauer-Emmett-Teller (BET) plot, and the total pore volume was calculated from the amount adsorbed at a relative pressure of about 0.98-0.99. Pore size distribution curves were obtained from the corresponding isotherms using the Barrett-Joyner-Halenda (BJH) method.

\subsection{Electrochemical measurements}

Electrochemical characterization of the samples was carried out using a high-power potentiostat (IviumStat, Ivium Technologies, Netherlands). The electrochemical experiments were performed at room temperature $\left(25^{\circ} \mathrm{C}\right)$ and under atmospheric pressure using a three-compartment electrochemical cell. A graphite rod counter electrode and $\mathrm{Hg} / \mathrm{HgO}$ reference electrode (XR400, Radiometer Analytical) with $1 \mathrm{M} \mathrm{KOH} \mathrm{(99.999 \% ,}$ Aldrich) filling solution were used. The $\mathrm{Hg} / \mathrm{HgO}$ reference electrode was calibrated with respect to the reversible hydrogen electrode (RHE) before use. For this purpose, Pt wires were used as both the working electrode and counter electrode, and the potential cycle between $-0.93 \mathrm{~V}$ and $-0.87 \mathrm{~V}(v s$. $\mathrm{Hg} / \mathrm{HgO})$ was applied with a scan rate of $1 \mathrm{mV} \mathrm{s}^{-1}$ in $\mathrm{H}_{2}$-saturated $0.1 \mathrm{M} \mathrm{KOH}$ solution. The resulting potential-current $(V-I)$ curve after averaging the anodic and cathodic currents gave a result of $E$ (RHE) $=E(\mathrm{Hg} / \mathrm{HgO})+0.887 \mathrm{~V}$. All potentials in this report were reported in the RHE scale.

For ORR performance measurement, a rotating ring disk electrode (RRDE) with a glassy carbon disk (GC, $4 \mathrm{~mm}$ in diameter) and a Pt ring (5 $\mathrm{mm}$ in inner diameter and $7 \mathrm{~mm}$ in outer diameter) was used as a working electrode (ALS, Cat. no. 012613). The RRDE was polished with 1.0 and $0.3 \mu \mathrm{m}$ alumina suspensions to generate a mirror finish. For preparation of a catalyst ink, Nafion (5 wt\% in isopropyl alcohol (IPA), Aldrich) was neutralized by $0.1 \mathrm{M} \mathrm{NaOH}(99.99 \%$, Aldrich) at a volume ratio of Nafion : $0.1 \mathrm{M} \mathrm{NaOH}=2: 1$ in order to prevent oxide passivation. ${ }^{44}$ Commercial carbon black (Vulcan XC-72R) was added to the catalyst ink to overcome the low electrical conductivity of oxides. The catalyst ink was prepared by mixing $5 \mathrm{mg}$ of catalyst, $12 \mathrm{mg}$ of Vulcan, $116 \mu \mathrm{L}$ of neutralized Nafion, $100 \mu \mathrm{L}$ of deionized water, and $0.98 \mathrm{~mL}$ of IPA (>99.9\%, Aldrich) with ultra-sonication for at least $30 \mathrm{~min} .3 \mu \mathrm{L}$ of the catalyst ink was deposited onto the GC electrode with a micro-syringe. The resulting catalyst loading was $0.1 \mathrm{mg}_{\text {oxide }} \mathrm{cm}^{-2}$. Prior to the electrochemical measurements, a potential cycle from 0.7 to 1.0 V was applied in a $\mathrm{N}_{2}$-saturated $0.1 \mathrm{M} \mathrm{KOH}$ solution for 50 cycles at a scan rate of $100 \mathrm{mV} \mathrm{s}^{-1}$ for electrochemical cleaning. Subsequently, the cyclic voltammogram was obtained under the same conditions used for electrochemical cleaning, except for the change in the scan rate of $20 \mathrm{mV} \mathrm{s}^{-1}$ for 3 cycles. Linear sweep voltammetry (LSV) curves for the ORR were obtained by cycling the potential from 1.1 to $0.2 \mathrm{~V}$ in an $\mathrm{O}_{2}$-saturated $0.1 \mathrm{M}$ $\mathrm{KOH}$ solution with $\mathrm{O}_{2}$ purging at different rotating speeds. The anodic and cathodic sweeps for the ORR were averaged in order to correct the capacitive-current contribution. ${ }^{\mathbf{4 4}}$ The ORR measurement was independently repeated three times, and the averaged currents were used.

For the evaluation of four-electron selectivity, the potential of the Pt ring was fixed at $1.3 \mathrm{~V}$ ( $v s$. RHE) during LSV scans for the 
ORR. The number of electrons transferred was calculated by the following equation:

$$
n=\frac{4}{1+\frac{I_{\mathrm{R}}}{N \times I_{\mathrm{D}}}}
$$

Here, $I_{\mathrm{D}}, I_{\mathrm{R}}$, and $N$ are the disk current, the ring current and the collection coefficient, respectively. The value of $N$ was measured in $1 \mathrm{M} \mathrm{KNO}_{3}+2 \mathrm{mM} \mathrm{K}_{3} \mathrm{Fe}(\mathrm{CN})_{6}$ at a rotating speed of $1000 \mathrm{rpm}$ and was determined to be 0.47 .

The four-electron selectivity was also assessed by the Koutecký-Levich equation:

$$
\frac{1}{I}=\frac{1}{I_{\mathrm{K}}}+\frac{1}{I_{\mathrm{L}}}=\frac{1}{I_{\mathrm{K}}}-\frac{1}{0.62 n F A D_{\mathrm{O}}^{2 / 3} \nu^{-1 / 6} C_{\mathrm{O}} \omega^{1 / 2}}
$$

Here, $I, I_{\mathrm{L}}$ and $I_{\mathrm{K}}$ are the measured current, the diffusion-limited current and the kinetic current, respectively. $F$ is the Faraday constant $\left(9.65 \times 10^{7} \mathrm{~mA} \mathrm{~s} \mathrm{~mol}^{-1}\right), A$ is the GC disk area $(0.126$ $\left.\mathrm{cm}^{2}\right), D_{\mathrm{O}}$ is the diffusion coefficient of $\mathrm{O}_{2}$ in $0.1 \mathrm{M} \mathrm{KOH}$ solution $\left(1.9 \times 10^{-5} \mathrm{~cm}^{2} \mathrm{~s}^{-1}\right), \nu$ is the kinematic viscosity of $0.1 \mathrm{M} \mathrm{KOH}$ $\left(0.01 \mathrm{~cm}^{2} \mathrm{~s}^{-1}\right), C_{\mathrm{O}}$ is the concentration of $\mathrm{O}_{2}$ in $0.1 \mathrm{M} \mathrm{KOH}(1.2$ $\left.\times 10^{-6} \mathrm{~mol} \mathrm{~cm}{ }^{-3}\right)$, and $\omega$ is the rotation speed of the unit in radian per second. ${ }^{\mathbf{4 5 - 4 7}}$

Before electrochemical impedance spectroscopy (EIS) measurement, the potential was cycled from 0.7 to $1.0 \mathrm{~V}$ for 50 cycles in $\mathrm{N}_{2}$-saturated $0.1 \mathrm{M} \mathrm{KOH}$ solution. Then, impedance spectra were obtained in $\mathrm{O}_{2}$-saturated $0.1 \mathrm{M} \mathrm{KOH}$ at a fixed potential of $0.7 \mathrm{~V}$ ( $v s$. RHE) in the frequency range varying from $10 \mathrm{kHz}$ to $0.05 \mathrm{~Hz}$.

\section{Results and discussion}

\subsection{Synthesis of Mn-MOF precursor}

We began with the synthesis of the Mn-MOF precursor. A solvothermal reaction of $\mathrm{Mn}\left(\mathrm{NO}_{3}\right)_{2} \cdot 4 \mathrm{H}_{2} \mathrm{O}$ and aliphatic ligand, meso-butane-1,2,3,4-tetracarboxylic acid ( $\left.\mathrm{H}_{4} \mathrm{BuTC}\right)$, in $\mathrm{N}, \mathrm{N}$ -
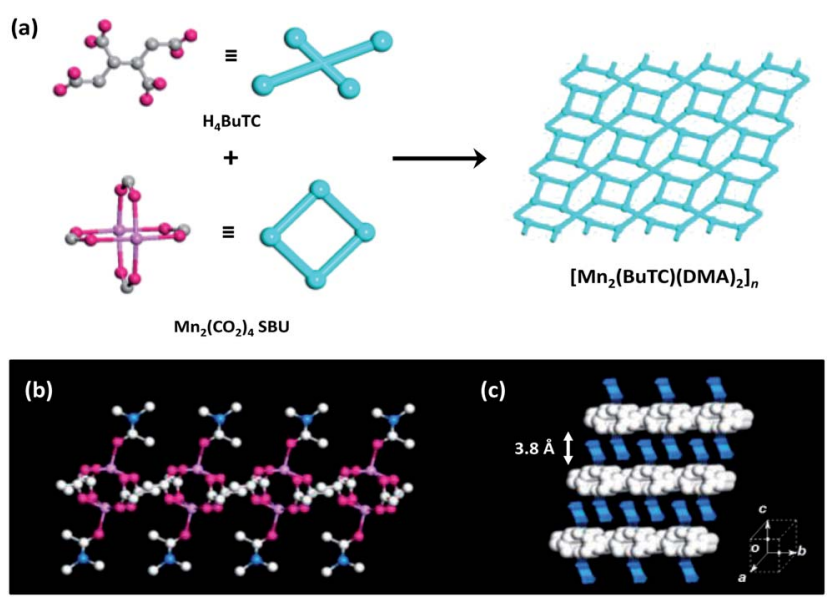

Fig. 2 Synthesis and single-crystal X-ray structure of Mn-MOF. (a) Synthetic scheme of Mn-MOF. (b) Side view of one layer of Mn-MOF. Hydrogen atoms and guest molecules are omitted for clarity (color scheme: $\mathrm{C}$, white; $\mathrm{O}$, purple; $\mathrm{N}$, light blue; $\mathrm{Mn}$, pink). (c) Entire structure of Mn-MOF (color scheme: 2-D layer, white; coordinating DMA, blue). dimethylacetamide (DMA) solvent at $100{ }^{\circ} \mathrm{C}$ for $24 \mathrm{~h}$ afforded yellowish leaf-shaped crystals of $\left[\mathrm{Mn}_{2}(\mathrm{BuTC})(\mathrm{DMA})_{2}\right]_{n}$ (Fig. 1 and 2). Single-crystal X-ray crystallographic data ${ }^{48}$ (Fig. 2 and S1 and Tables $\mathrm{S} 1$ and $\mathrm{S} 2 \dagger$ ) revealed that $\mathrm{Mn}-\mathrm{MOF}$ is constructed with $\mathrm{Mn}_{2}(\mathrm{COO})_{4}$ paddle-wheel clusters as secondary building units interconnected by the BuTC ligand to form a 2-dimensional layer. In the Mn-MOF, each $\mathrm{Mn}^{\mathrm{II}}$ ion is coordinated with four oxygen atoms of four different BuTC ligands in the equatorial positions and an oxygen atom of a DMA molecule at the axial position to show a square-pyramidal coordination geometry. Four carboxylate groups of four different BuTC ligands bridge between the two $\mathrm{Mn}^{\text {II }}$ centers in a syn-syn bidentate mode, forming a paddle-wheel shaped SBU. The Mn-Mn distance in a SBU is 3.051(1) A. Each BuTC ${ }^{4-}$ acts as a tetrabidentate bridging ligand by coordinating to eight different $\mathrm{Mn}^{\mathrm{II}}$ centers. The shortest interlayer distance is $3.8 \AA$, based on the van der Waals radii. The XRPD pattern of $\left[\mathrm{Mn}_{2}(\mathrm{BuTC})(\mathrm{D}\right.$ $\left.\mathrm{MA})_{2}\right]_{n}$ showed good agreement with the simulated pattern (Fig. S2 $\dagger$ ). In the TGA trace of the as-synthesized Mn-MOF in a $\mathrm{N}_{2}$ atmosphere (Fig. S3 $\dagger$ ), the two coordinating DMA molecules per formula $\left(\left[\mathrm{Mn}_{2}(\mathrm{BuTC})(\mathrm{DMA})_{2}\right]_{n}\right)$ were removed over the range 200-300 ${ }^{\circ} \mathrm{C}$, and decomposition of Mn-MOF ensued above $\sim 400{ }^{\circ} \mathrm{C}$.

\subsection{Conversion reactions of Mn-MOF into manganese oxides and their characterization}

We explored the conversion reactions of Mn-MOF into manganese oxides. Based on the above TGA result, we first heated as-synthesized Mn-MOF under $\mathrm{N}_{2}$ flow to $550{ }^{\circ} \mathrm{C}$ and maintained this temperature for $12 \mathrm{~h}$ to achieve complete thermal decomposition of the MOF structure (see the ESI $\dagger$ ). Scanning electron microscope (SEM) images of pristine MnMOF and converted black powder revealed a pseudomorphic conversion process (Fig. 1). The converted material was nanoporous, as its cross-sectional SEM and TEM images (Fig. 3a and d) clearly showed the macropores and mesopores, respectively. The TEM image revealed that the frameworks of the converted material were composed of small nanoparticles of $\sim 5 \mathrm{~nm}$. A high-resolution (HR) TEM image of this material (Fig. 3d, inset) exhibited distinct lattice fringes indicating the highly crystalline nature of these nanoparticles. The XRPD pattern of the converted material identifies its structure as single-phase cubic manganosite (MnO), which is coincident with JCPDS no. 71-4748 (Fig. 4, bottom). The cubic MnO phase could be confirmed by its electron diffraction pattern (Fig. 3d, inset) as well. The crystalline size of MnO nanoparticles, calculated by applying the Scherrer equation to the (200) reflection, was $5.0 \mathrm{~nm}$ in diameter. The elemental analysis revealed that the nanoporous $\mathrm{MnO}$ contained residual carbon (18 wt\%) and nitrogen (0.6 wt\%).

Using the nanoporous $\mathrm{MnO}$ that has the lowest oxidation state among the manganese oxide structures as a precursor, we further carried out sequential conversion reactions in an oxidizing environment to generate manganese oxides with higher oxidation states. First, nanoporous MnO was heated in ambient air. The XRPD patterns monitored at incremental 

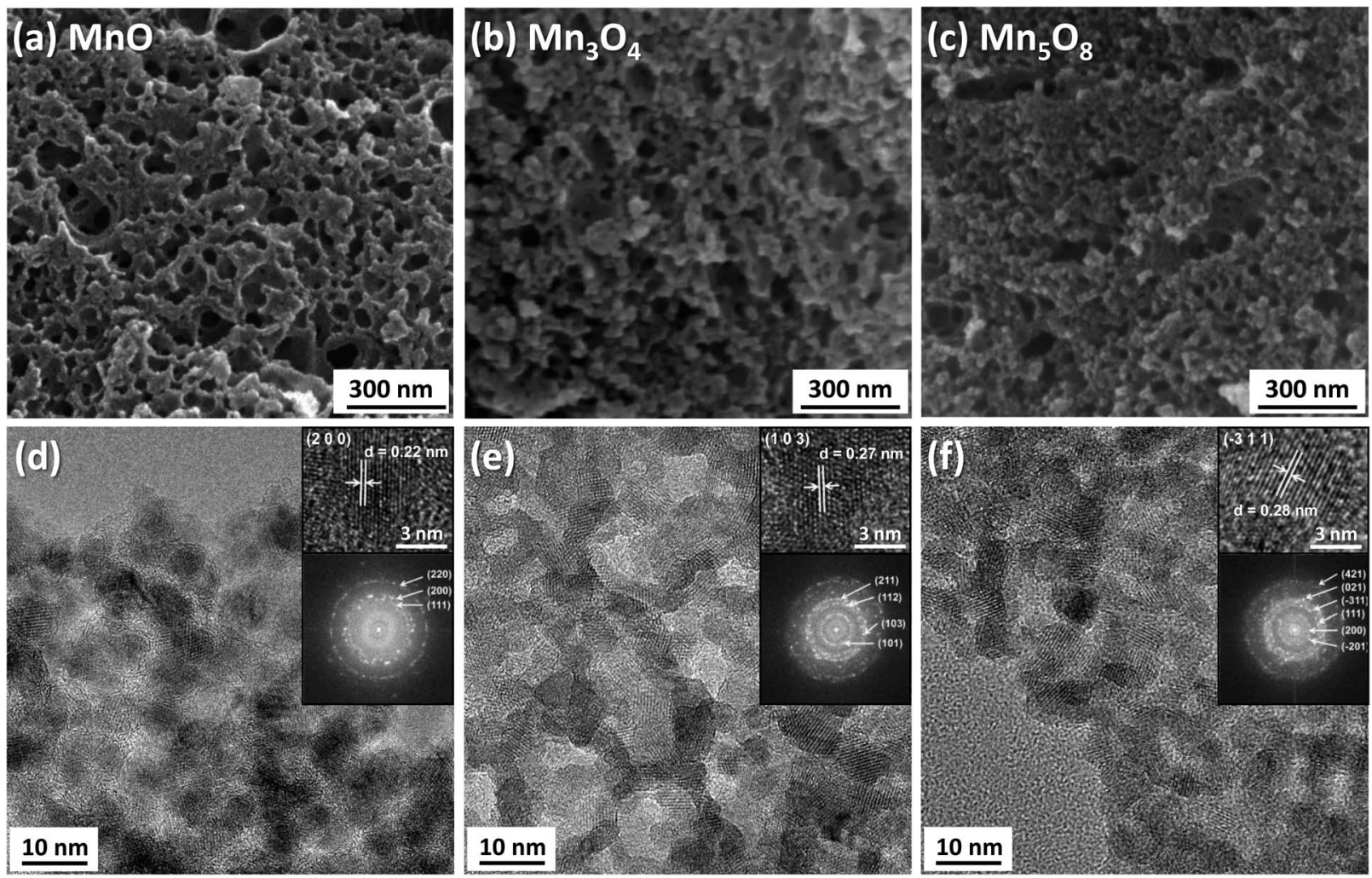

Fig. 3 Characterization of converted manganese oxides. (a-c) SEM images, $(d-f)$ TEM images, and (d-f, insets) HR-TEM images and electron diffraction patterns of nanoporous $\mathrm{MnO}$ ( $a$ and $d$ ), $\mathrm{Mn}_{3} \mathrm{O}_{4}$ ( $b$ and $e$ ), and $\mathrm{Mn}_{5} \mathrm{O}_{8}$ (c and f).

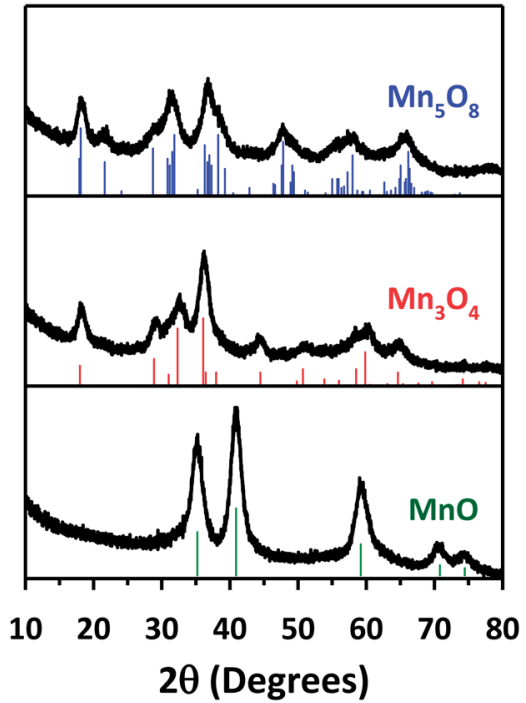

Fig. 4 XRPD patterns of converted manganese oxides.

heating temperatures (Fig. 5a) indicated that the transformation of cubic $\mathrm{MnO}$ into tetragonal spinel-phase hausmannite- $\mathrm{Mn}_{3} \mathrm{O}_{4}$ (JCPDS no. 24-0734, hereafter $\mathrm{Mn}_{3} \mathrm{O}_{4}$ ) started at $100{ }^{\circ} \mathrm{C}$, and the latter phase was maintained up to $300{ }^{\circ} \mathrm{C}$. At $350^{\circ} \mathrm{C}$, several new peaks started to appear in the XRPD pattern, which correspond to bixbyite $\mathrm{Mn}_{2} \mathrm{O}_{3}$ (JCPDS no. 73-1826). Further heating to $\geq 450{ }^{\circ} \mathrm{C}$ yielded the pure phase of $\mathrm{Mn}_{2} \mathrm{O}_{3}$.

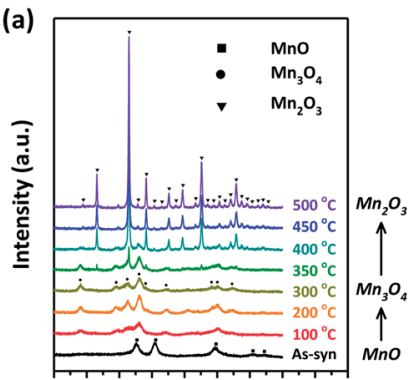

102030405060708090100 $2 \theta$ (Degrees)

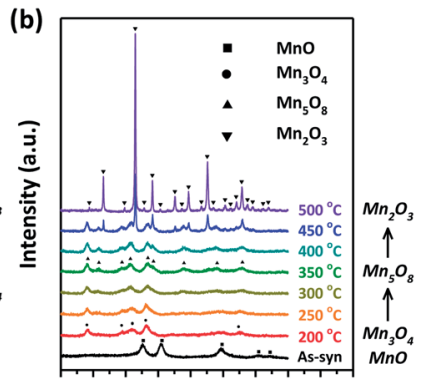

102030405060708090100 $2 \theta$ (Degrees)

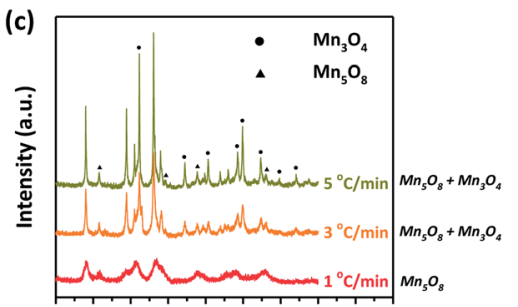

$\begin{array}{llllllllll}10 & 20 & 30 & 40 & 50 & 60 & 70 & 80 & 90 & 100\end{array}$

$$
2 \theta \text { (Degrees) }
$$

Fig. 5 Monitoring structural transformations from $\mathrm{MnO}$ to manganese oxides with higher oxidation numbers. XRPD patterns for $\mathrm{MnO}$ before and after heat treatment at various temperatures (a) in a box furnace with a ramping rate of $5^{\circ} \mathrm{C} \mathrm{min}^{-1}$ and (b) in a tube furnace under an oxygen flow of $100 \mathrm{~mL} \mathrm{~min}{ }^{-1}$ with a ramping rate of $1^{\circ} \mathrm{C} \mathrm{min}{ }^{-1}$. (c) XRPD patterns of $\mathrm{MnO}$ after heat treatment at $350^{\circ} \mathrm{C}$ in a tube furnace

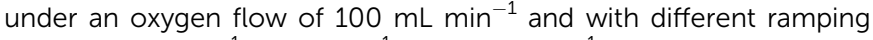
rates of $1^{\circ} \mathrm{C} \min ^{-1}, 3{ }^{\circ} \mathrm{C} \min ^{-1}$, and $5^{\circ} \mathrm{C} \mathrm{min}^{-1}$. 
Meanwhile, conversion reactions in a more oxidative environment allowed for the stabilization of metastable intermediate $\mathrm{Mn}_{5} \mathrm{O}_{8}$; we found that the nanoporous $\mathrm{MnO}$ can be transformed into a pure, layered $\mathrm{Mn}_{5} \mathrm{O}_{8}$ phase by way of the $\mathrm{Mn}_{3} \mathrm{O}_{4}$ phase, when it was heated to $350{ }^{\circ} \mathrm{C}$ under oxygen flow at a very slow ramping rate of $1^{\circ} \mathrm{C} \mathrm{min}^{-1}$ (Fig. $5 \mathrm{~b}$ and $\mathrm{c}$ ). The heating of $\mathrm{MnO}$ to the same temperature but with higher ramping rates (3 or $5{ }^{\circ} \mathrm{C} \min ^{-1}$ ) afforded a mixture of $\mathrm{Mn}_{3} \mathrm{O}_{4}$ and $\mathrm{Mn}_{5} \mathrm{O}_{8}$ phases instead of the sequential formation of pure $\mathrm{Mn}_{3} \mathrm{O}_{4}$ and $\mathrm{Mn}_{5} \mathrm{O}_{8}$ phases (Fig. 5c). Hence, the degree of oxidation environment and the change of heating rate can adjust oxidation states and purities of the resultant manganese oxides.

Under the optimized experimental conditions based on the above experiments, we could obtain $\mathrm{Mn}_{3} \mathrm{O}_{4}$ and $\mathrm{Mn}_{5} \mathrm{O}_{8}$ in pure phases via pseudomorphic transformation of nanoporous $\mathrm{MnO}$ (Fig. 1). Further examination of these two manganese oxides with cross-sectional SEM and TEM images (Fig. 3b, c, e and f) revealed that the nanoporous structure of $\mathrm{MnO}$ was retained despite the structural transformation processes. The crystalline sizes of $\mathrm{Mn}_{3} \mathrm{O}_{4}$ and $\mathrm{Mn}_{5} \mathrm{O}_{8}$, calculated by applying the Scherrer equation to the $(101)$ and $(-201)$ reflections of their XRPD patterns (Fig. 4), respectively, were $5.6 \mathrm{~nm}$ and $5.2 \mathrm{~nm}$, similar to those of MnO. The crystallinity and pure phases of nanoporous $\mathrm{Mn}_{3} \mathrm{O}_{4}$ and $\mathrm{Mn}_{5} \mathrm{O}_{8}$ were also confirmed by their HR-TEM images and electron diffraction patterns (Fig. 3e and $\mathrm{f}$, insets), respectively. However, $\mathrm{Mn}_{2} \mathrm{O}_{3}$ showed a marked increase in the nanocrystal size, from 5.0 to $\sim 20 \mathrm{~nm}$, regardless of the reaction conditions such as the gas environment or heating rate (Fig. 5a and $\mathrm{b}$ and $\mathrm{S} 5 \dagger)$. Hereafter, we will focus on the three phases$\mathrm{MnO}, \mathrm{Mn}_{3} \mathrm{O}_{4}$, and $\mathrm{Mn}_{5} \mathrm{O}_{8}$ - that have almost identical textural properties, for further discussion of the converted manganese oxides.

Fig. 6 shows the nitrogen adsorption-desorption isotherms of the three manganese oxides, which feature type IV isotherms with H3-type hysteresis loops over all three samples, indicating

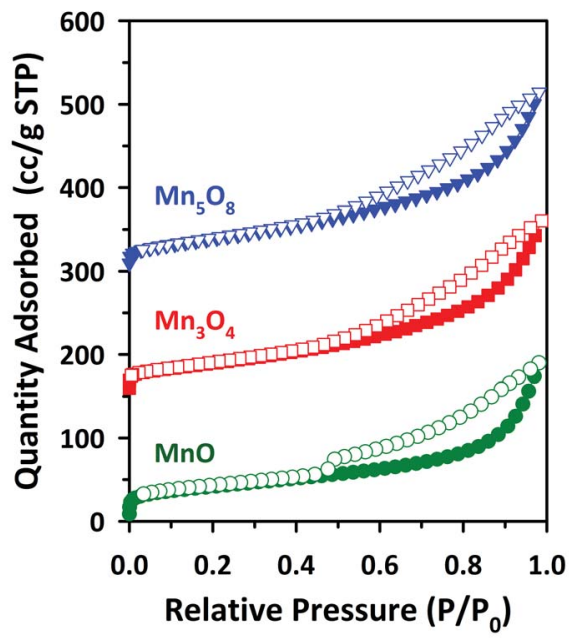

Fig. 6 Nitrogen adsorption-desorption isotherms of converted manganese oxides. well-developed mesoporosity. The highly porous nature of the three nanoporous manganese oxides provide similarly large Brunauer-Emmett-Teller (BET) surface areas $\left(\sim 145 \mathrm{~m}^{2} \mathrm{~g}^{-1}\right)$ and pore volumes $\left(\sim 0.3 \mathrm{~cm}^{3} \mathrm{~g}^{-1}\right)$. The pore size distribution curves obtained by the $\mathrm{BJH}$ method exhibited similar pores sizes (5 to $20 \mathrm{~nm}$ ) of manganese oxides (Fig. $\mathrm{S} 4 \dagger$ ). The detailed textural data are summarized in Table S3. $\dagger$ While the $\mathrm{N}_{2}$ adsorption data reveal similar porous properties of the three manganese oxides, the X-ray photoelectron spectroscopy (XPS) data clearly establish a marked difference in their oxidation states (Fig. 7 and Table S4†). The Mn 3s XPS spectra (Fig. 7) revealed that the position of the lower binding energy peak gradually shifted to higher energy with the increase in the oxidation number of the sample ( $\mathrm{MnO} \rightarrow \mathrm{Mn}_{3} \mathrm{O}_{4} \rightarrow \mathrm{Mn}_{5} \mathrm{O}_{8}$ ), which is consistent with previous results. ${ }^{49-51}$ This systematic peak shift results in a corresponding decrease in the $3 \mathrm{~s}$ multiplet splitting $\left(\Delta E_{3 \mathrm{~s}}\right)$ of these manganese oxides (Table $\mathrm{S} 4 \dagger$ ).

Nanoporous manganese oxides thus far reported have been predominantly limited to those with high oxidation states such as $\mathrm{MnO}_{2}$ and $\mathrm{Mn}_{2} \mathrm{O}_{3} \cdot{ }^{9,52-58}$ Toward the low-oxidation-state manganese oxide, Bruce et al. prepared nanoporous $\mathrm{Mn}_{3} \mathrm{O}_{4}$ by reducing pre-synthesized nanoporous $\mathrm{Mn}_{2} \mathrm{O}_{3}$ with hydrogen gas. $^{58}$ Likewise, other nanoporous metal oxides with low oxidation states, for instance, $\mathrm{CoO}$ and $\mathrm{Fe}_{3} \mathrm{O}_{4}$, could be prepared by the reduction of the corresponding metal oxides with higher oxidation numbers. ${ }^{59,60}$ In contrast, in our approach, the oxidative conversion reactions of Mn-MOF could sequentially generate nanoporous $\mathrm{MnO}, \mathrm{Mn}_{3} \mathrm{O}_{4}, \mathrm{Mn}_{5} \mathrm{O}_{8}$, and $\mathrm{Mn}_{2} \mathrm{O}_{3}$, by progressively increasing the degree of oxidation. Significantly, our MOF-driven route enabled the isolation of the low-oxidation-state $\mathrm{MnO}$ and metastable intermediate $\mathrm{Mn}_{5} \mathrm{O}_{8}$ as pure phases with nanoporous nanocrystalline structures, which were previously rarely attainable. ${ }^{61,62}$ In particular, to our knowledge, nanoporous $\mathrm{Mn}_{5} \mathrm{O}_{8}$ with such a large surface area and well-developed porosity is prepared for the first time.

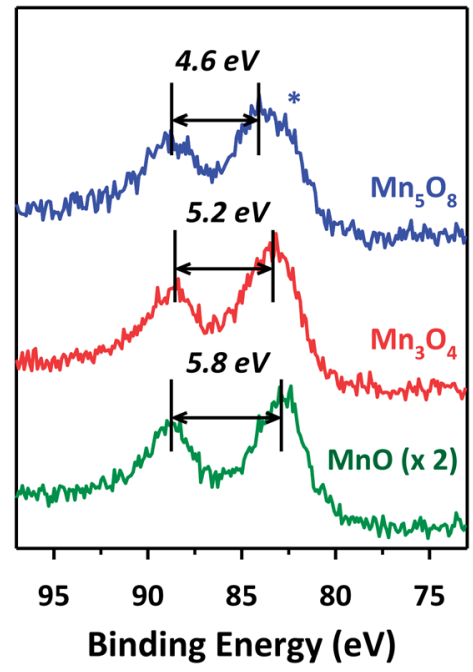

Fig. $7 \mathrm{Mn} 3 \mathrm{~s}$ XPS spectra of converted manganese oxides. The blue asterisk indicates the presence of low-valent (e.g. $\mathrm{Mn}^{2+}$ ) manganese species in $\mathrm{Mn}_{5} \mathrm{O}_{8}$. 
We note that the transformations between different structures, from cubic $(\mathrm{MnO})$ to spinel $\left(\mathrm{Mn}_{3} \mathrm{O}_{4}\right)$, and to layered $\left(\mathrm{Mn}_{5} \mathrm{O}_{8}\right)$, occurred while preserving a nanoporous structure and textural properties. As demonstrated in our recent work, ${ }^{30}$ the conversion reactions exploiting aliphatic ligand-based MOFs allow for the formation of thermally stable nanoporous metal oxide frameworks that are composed of small nanoparticles. In this approach, labile aliphatic ligands can act as self-templates during the thermal conversion process, and finally evaporate to generate nanopores. We also found that the infinite coordination between inorganic and organic moieties in the MOFs is critical for suppressing the aggregation of metallic entities into large particles; instead, the thermal conversion of a single coordination compound generated very large agglomerates. ${ }^{\mathbf{3 1}} \mathrm{In}$ this way, the prepared nanoporous manganese oxide frameworks are constructed with small $(\sim 5 \mathrm{~nm})$ manganese oxide nanoparticles, which have a high density of defects or grain boundaries. Compared to bulk metal oxides, nanometer scale manganese oxide nanoparticles could relieve or minimize the structural stress during the transformations between different structures, which could lead to a minimal change in their textural properties.

\subsection{Electrocatalytic properties of nanoporous manganese oxides for oxygen reduction reaction}

Among the transformed nanoporous manganese oxides, $\mathrm{Mn}_{3} \mathrm{O}_{4}$ and $\mathrm{Mn}_{5} \mathrm{O}_{8}$ have nearly identical textural properties (such as morphology, surface area, and crystallite size of framework
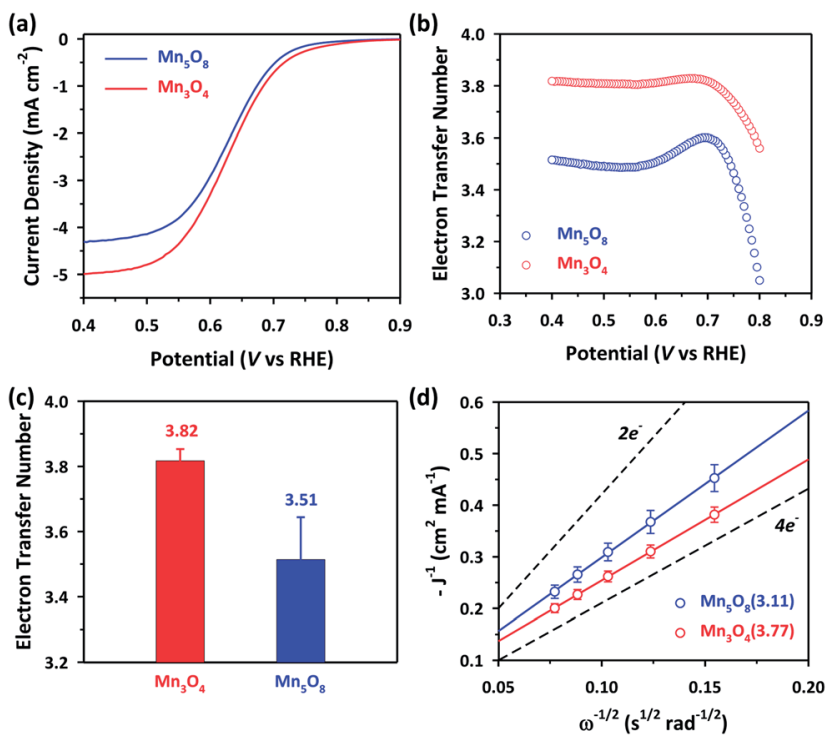

Fig. 8 Electrocatalytic activity of a series of nanoporous manganese oxides for the ORR. (a) LSV curves of nanoporous manganese oxides on glassy carbon electrodes. (b) The numbers of electrons transferred at $0.4 \mathrm{~V}$ (vs. RHE) during the ORR obtained from the RRDE measurements. (c) Plot of the number of transferred electrons against potential during the ORR obtained by RRDE measurement. (d) Koutecký-Levich plots at $0.4 \mathrm{~V}$ (vs. RHE). The dotted lines show the theoretical slopes when two and four electrons are transferred during ORR. The numbers in the parentheses indicate the number of transferred electrons. nanoparticles) and are free of residual carbon, but differ only in their oxidation states. As such, these two manganese oxides can serve as a system for the study of the oxidation state effect in catalysis. We investigated the electrocatalytic properties of the two nanoporous manganese oxides for the ORR (Fig. 8, S6, and $\mathrm{S} 7 \dagger$ ), because the latter is a key reaction in energy conversion devices such as fuel cells and metal-air batteries. The LSV curves for the two nanoporous manganese oxides (Fig. 8a) measured in the $0.1 \mathrm{M} \mathrm{KOH}$ electrolyte at a rotating speed of $1600 \mathrm{rpm}$ revealed that the nanoporous $\mathrm{Mn}_{3} \mathrm{O}_{4}$ had higher onset potential $(0.75 \mathrm{~V}$ vs. RHE) and current density at $0.75 \mathrm{~V}$ $\left(-0.26 \mathrm{~mA} \mathrm{~cm}{ }^{-2}\right)$ than $\mathrm{Mn}_{5} \mathrm{O}_{8}\left(0.73 \mathrm{~V}\right.$ and $-0.15 \mathrm{~mA} \mathrm{~cm}{ }^{-2}$, respectively). In addition, nanoporous $\mathrm{Mn}_{3} \mathrm{O}_{4}$ showed a higher limiting current density than $\mathrm{Mn}_{5} \mathrm{O}_{8}$. We note that nanoporous MnO showed higher current density than the other oxides in the kinetic-diffusion controlled region of the LSV curve (Fig. S8†). This result does not correspond to the previous report where MnO exhibited inferior ORR activity to $\mathrm{Mn}_{3} \mathrm{O}_{4} \cdot{ }^{63}$ We attribute this higher activity of the nanoporous $\mathrm{MnO}$ to the presence of residual carbon and nitrogen. The kinetic parameters of the two catalysts for the ORR were deduced by measurement of the ring currents during the ORR (Fig. 8b and c) and the KouteckýLevich analyses (Fig. 8d and S6†). Results from both the methods consistently indicated that the electron numbers transferred by the nanoporous $\mathrm{Mn}_{3} \mathrm{O}_{4}$ were higher (3.8) than those of $\mathrm{Mn}_{5} \mathrm{O}_{8}$ (3.1-3.5). The excellent kinetics observed for nanoporous $\mathrm{Mn}_{3} \mathrm{O}_{4}$ could also be confirmed with its smaller charge transfer resistance at $0.7 \mathrm{~V}$ in EIS data (Fig. S7 $\dagger$ ).

Collectively, nanoporous $\mathrm{Mn}_{3} \mathrm{O}_{4}$ had higher diffusionlimited current, electron transfer number, and lower charge transfer resistance than $\mathrm{Mn}_{5} \mathrm{O}_{8}$. For the ORR in an alkaline electrolyte, the most efficient way is the direct four electron transfer mechanism, which is, however, kinetically impeded due to its high activation barrier. Instead, a two-step mechanism is favored, wherein oxygen is first reduced via a two electron pathway producing peroxide species $\left(\mathrm{HO}_{2}{ }^{-}\right)$and the catalytic decomposition of $\mathrm{HO}_{2}{ }^{-}$produces half of oxygen molecule that is further reduced. Importantly, rapidly repeating the latter cycles lead to the quasi-four-electron transfer mechanism. Comparing the oxidation state of the two manganese oxides, the spinel $\mathrm{Mn}_{3} \mathrm{O}_{4}$ structure consists of $\mathrm{Mn}$ cations with +2 and +3 oxidation numbers, whereas layered $\mathrm{Mn}_{5} \mathrm{O}_{8}$ has +2 and +4 oxidation states. The decomposition of $\mathrm{HO}_{2}{ }^{-}$can be facilitated by the facile redox mechanism between +2 and $+3 \mathrm{Mn}$ cations on the surface of the $\mathrm{Mn}_{3} \mathrm{O}_{4}$ structure. ${ }^{64}$ Such enhanced $\mathrm{HO}_{2}{ }^{-}$decomposition results in quasi-four-electron transfer with nanoporous $\mathrm{Mn}_{3} \mathrm{O}_{4}$. It is suggested that the disparity in the framework structure between $\mathrm{Mn}_{3} \mathrm{O}_{4}$ and $\mathrm{Mn}_{5} \mathrm{O}_{8}$ could also contribute to the difference in their ORR activity. Layered $\mathrm{Mn}_{5} \mathrm{O}_{8}$ is constructed with dense frameworks, which can impede facile adsorption of oxygen molecules. In contrast, spinel $\mathrm{Mn}_{3} \mathrm{O}_{4}$ with a relatively opened framework is favorable for oxygen adsorption, thus expediting catalytic cycles. Likewise, a recent study revealed that among a series of calcium manganese oxides, $\mathrm{Ca}_{2} \mathrm{Mn}_{3} \mathrm{O}_{8}$ that has an analogous crystal structure to $\mathrm{Mn}_{5} \mathrm{O}_{8}$ exhibited lowest ORR activity. ${ }^{65}$ 


\section{Conclusions}

In summary, conversion reactions using the Mn-MOF precursor yielded a series of nanoporous manganese oxide structures via sequential transformations. Significantly, this transformative route allowed for the preparation of low-oxidation-state (MnO) and metastable intermediate $\left(\mathrm{Mn}_{5} \mathrm{O}_{8}\right)$ phases while having nanoporous architecture, which were otherwise difficult to synthesize. Additionally, this method enabled facile structural transformations between different manganese oxide structures while preserving their structural properties. In comparative investigation of the electrocatalytic activity of nanoporous manganese oxides, $\mathrm{Mn}_{3} \mathrm{O}_{4}$ showed better ORR activity and kinetics than nanoporous $\mathrm{Mn}_{5} \mathrm{O}_{8}$, demonstrating an important role of the oxidation state for enhanced performance of the ORR.

Together with our recent work, ${ }^{30}$ conversion reactions exploiting aliphatic ligand-based MOFs have been demonstrated as a versatile route to nanoporous metal oxides with nanocrystalline frameworks. This work, in particular, has shown that this transformative route can enable the preparation of nanoporous architectures with unexplored compositions. We envisage that further investigations into the MOF-driven conversion reactions can enrich the composition, structure, and function of nanoporous metal oxide materials.

\section{Acknowledgements}

This work was supported by the Korea CCS R\&D Center (KCRC) grant funded by the Korean Ministry of Science, ICT \& Future Planning (NRF-2013M1A8A1039968) and by the Basic Science Research Program through the National Research Foundation of Korea (2013R1A1A2012960). J.H.L. and Y.J.S. acknowledge the Global PhD Fellowship (NRF-2013H1A2A1033501 and NRF2013H1A2A1032644, respectively). The authors acknowledge PAL for beamline use (Grant 2013-2nd-2D-003).

\section{Notes and references}

1 F. Schüth, Chem. Mater., 2001, 13, 3184-3195.

2 G. J. A. A. Soler-Illia, C. Sanchez, B. Lebeau and J. Patarin, Chem. Rev., 2002, 102, 4093-4138.

3 H. Yang and D. Zhao, J. Mater. Chem., 2005, 15, 1217-1231.

4 Y. Ren, Z. Ma and P. G. Bruce, Chem. Soc. Rev., 2012, 41, 4909-4927.

5 D. Gu and F. Schüth, Chem. Soc. Rev., 2013, 43, 313-344.

6 Q. Huo, D. I. Margolese, U. Ciesla, P. Feng, T. E. Gier, P. Sieger, R. Leon, P. M. Petroff, F. Schüth and G. D. Stucky, Nature, 1994, 368, 317-321.

7 D. M. Antonelli and J. Y. Ying, Angew. Chem., Int. Ed., 1995, 34, 2014-2017.

8 P. Yang, D. Zhao, D. I. Margolese, B. F. Chmelka and G. D. Stucky, Nature, 1998, 396, 152-155.

9 D. Grosso, C. Boissière, B. Smarsly, T. Brezesinski, N. Pinna, P. A. Albouy, H. Amenitsch, M. Antonietti and C. Sanchez, Nat. Mater., 2004, 3, 787-792.
10 B. Tian, X. Liu, H. Yang, S. Xie, C. Yu, B. Tu and D. Zhao, Adv. Mater., 2003, 15, 1370-1374.

11 S. C. Laha and R. Ryoo, Chem. Commun., 2003, 2138-2139.

12 J. Lee, M. C. Orilall, S. C. Warren, M. Kamperman, F. J. DiSalvo and U. Wiesner, Nat. Mater., 2008, 7, 222-228.

13 A. Corma, P. Atienzar, H. Garcia and J.-Y. Chane-Ching, Nat. Mater., 2004, 3, 394-397.

14 R. Buonsanti, T. E. Pick, N. Krins, T. J. Richardson, B. A. Helms and D. J. Milliron, Nano Lett., 2012, 12, 38723877.

15 Y. Vasquez, A. E. Henkes, J. C. Bauer and R. E. Schaak, J. Solid State Chem., 2008, 181, 1509-1523.

16 M. Kim, V. N. Phan and K. Lee, CrystEngComm, 2012, 14, 7535-7548.

17 B. J. Beberwyck, Y. Surendranath and A. P. Alivisatos, J. Phys. Chem. C, 2013, 117, 19759-19770.

18 W. Wang, M. Dahl and Y. Yin, Chem. Mater., 2013, 25, 11791189.

19 J. H. Han, S. Lee and J. Cheon, Chem. Soc. Rev., 2013, 42, 2581-2591.

20 Y. Yin, R. M. Rioux, C. K. Erdonmez, S. Hughes, G. A. Somorjai and A. P. Alivisatos, Science, 2004, 304, 711714.

21 Y. Sun and Y. Xia, Science, 2002, 298, 2176-2179.

22 B. Liu, H. Shioyama, T. Akita and Q. Xu, J. Am. Chem. Soc., 2008, 130, 5390-5391.

23 S. J. Yang and C. R. Park, Adv. Mater., 2012, 24, 4010-4013.

24 M. Hu, J. Reboul, S. Furukawa, N. L. Torad, Q. M. Ji, P. Srinivasu, K. Ariga, S. Kitagawa and Y. Yamauchi, J. Am. Chem. Soc., 2012, 134, 2864-2867.

25 W. Cho, S. Park and M. Oh, Chem. Commun., 2011, 47, 41384140.

26 X. Xu, R. Cao, S. Jeong and J. Cho, Nano Lett., 2012, 12, 49884991.

27 L. Zhang, H. B. Wu, S. Madhavi, H. H. Hng and X. W. Lou, J. Am. Chem. Soc., 2012, 134, 17388-17391.

$28 \mathrm{M} . \mathrm{Hu}, \mathrm{A}$. A. Belik, M. Imura and Y. Yamauchi, J. Am. Chem. Soc., 2013, 135, 384-391.

29 A. S. Hall, A. Kondo, K. Maeda and T. E. Mallouk, J. Am. Chem. Soc., 2013, 135, 16276-16279.

30 T. K. Kim, K. J. Lee, J. Y. Cheon, J. H. Lee, S. H. Joo and H. R. Moon, J. Am. Chem. Soc., 2013, 135, 8940-8946.

31 L. Guo, H. Arafune and N. Teramae, Langmuir, 2013, 29, 4404-4412.

32 A. H. Reidies, Manganese Compounds, in Ullmann's Encyclopedia of Industrial Chemistry, Wiley-VCH, Weinheim, 6 edn, 2002, vol. 20, pp. 543-564.

33 H. Wang, L.-F. Cui, Y. Yang, H. S. Casalongue, J. T. Robinson, Y. Liang, Y. Cui and H. Dai, J. Am. Chem. Soc., 2010, 132, 13978-13980.

34 J.-S. Lee, G. S. Park, H. I. Lee, S. T. Kim, R. Cao, M. Liu and J. Cho, Nano Lett., 2011, 11, 5362-5366.

35 W. Wei, X. Cui, W. Chen and D. G. Ivey, Chem. Soc. Rev., 2011, 40, 1697-1721.

36 F. Jiao and H. Frei, Chem. Commun., 2010, 46, 2920-2922.

37 L. Mao, T. Sotomura, K. Nakatsu, N. Koshiba, D. Zhang and T. Ohsaka, J. Electrochem. Soc., 2002, 149, A504-A507. 
38 L. Mao, D. Zhang, T. Sotomura, K. Nakatsu, N. Koshiba and T. Ohsaka, Electrochim. Acta, 2003, 48, 1015-1021.

39 F. H. B. Lima, M. L. Calegaro and E. A. Ticianelli, J. Electroanal. Chem., 2006, 590, 152-160.

40 F. H. B. Lima, M. L. Calegaro and E. A. Ticianelli, Electrochim. Acta, 2007, 52, 3732-3738.

41 A. J. Arvai and C. Nielsen, ADSC Quantum-210 ADX Program, Area Detector System Corporation, Poway, CA, USA, 1983.

42 Z. Otwinowski and W. Minor, Methods in Enzymology, Part A, in Macromolecular Crystallography, ed. C. W. Carter Jr. and R. M. Sweet, Academic Press, New York, 1997, vol. 276, pp. 307-326.

43 G. M. Sheldrick, SHELXTL-PLUS, Crystal Structure Analysis Package, Bruker Analytical X-Ray, Madison, WI, USA, 1997.

44 J. Suntivich, H. A. Gasteiger, N. Yabuuchi and Y. Shao-Horn, J. Electrochem. Soc., 2010, 157, B1263-B1268.

45 Z.-W. Liu, F. Peng, H.-J. Wang, H. Yu, W.-X. Zheng and J. Yang, Angew. Chem., Int. Ed., 2011, 50, 3257-3261.

46 W. Yang, T.-P. Fellinger and M. Antonietti, J. Am. Chem. Soc., 2011, 133, 206-209.

47 S. Wang, D. Yu and L. Dai, J. Am. Chem. Soc., 2011, 133, 51825185.

48 Crystal data for $\mathrm{Mn}_{2} \mathrm{C}_{16} \mathrm{~N}_{2} \mathrm{O}_{10} \mathrm{H}_{24}, M_{\mathrm{r}}=514.25$, triclinic, space group $P \overline{1}$ (no. 2), $a=6.473(13), b=7.970(16), c=$ $10.577(2) \AA, \alpha=101.69(3)^{\circ}, \beta=102.84(3)^{\circ}, \gamma=105.70(3)^{\circ}$, $V=491.7(17) \AA^{3}, Z=1, d_{\text {calcd }}=1.737 \mathrm{~g} \mathrm{~cm}^{-3}, T=100(2)$ $\mathrm{K}$, crystal size $0.2 \times 0.2 \times 0.1 \mathrm{~mm}^{3}, \lambda=0.69999 \AA, 2 \theta=$ 67.92, 136 parameters, $R_{1}=0.0379(I>2 \sigma(I), 2865$ reflections), $w R_{2}=0.1082$ (all data, 5533 reflections), GOF $=1.093$. Crystallographic data are summarized in the ESI. $\dagger$

49 M. Oku, K. Hirokawa and S. Ikeda, J. Electron Spectrosc. Relat. Phenom., 1975, 7, 465-473.

50 V. Di Castro and G. Polzonetti, J. Electron Spectrosc. Relat. Phenom., 1989, 48, 117-123.
51 T. Gao, P. Norby, F. Krumeich, H. Okamoto, R. Nesper and H. Fjellvag, J. Phys. Chem. C, 2010, 114, 922-928.

52 Z.-R. Tian, W. Tong, J.-Y. Wang, N.-G. Duan, V. V. Krishnan and S. L. Suib, Science, 1997, 276, 926-930.

53 A.-S. Malik, M. J. Duncan and P. G. Bruce, J. Mater. Chem., 2003, 13, 2123-2126.

54 A. K. Sinha, K. Suzuki, M. Takahara, H. Azuma, T. Nonaka and K. Fukumoto, Angew. Chem., Int. Ed., 2007, 46, 28912894.

55 M. Imperor-Clerc, D. Bazin, M. D. Appay, P. Beaunier and A. Davidson, Chem. Mater., 2004, 16, 1813-1821.

56 J.-Y. Luo, J.-J. Zhang and Y.-Y. Xia, Chem. Mater., 2006, 18, 5618-5623.

57 F. Jiao and P. G. Bruce, Adv. Mater., 2007, 19, 657660.

58 F. Jiao, A. Harrison, A. H. Hill and P. G. Bruce, Adv. Mater., 2007, 19, 4063-4066.

59 F. Jiao, J.-C. Jumas, M. Womes, A. V. Chadwick, A. Harrison and P. G. Bruce, J. Am. Chem. Soc., 2006, 128, 1290512909.

60 H. Tüysüz, Y. Liu, C. Weidenthaler and F. Schüth, J. Am. Chem. Soc., 2008, 130, 14108-14110.

61 G.-L. Xu, Y.-F. Xu, J.-C. Fang, F. Fu, H. Sun, L. Huang, S. Yang and S.-G. Sun, ACS Appl. Mater. Interfaces, 2013, 5, 63166323.

62 S. S. T. Bastos, J. J. M. Orfao, M. M. A. Freitas, M. F. R. Pereira and J. L. Figueiredo, Appl. Catal., B, 2009, 93, 30-37.

63 Y. Gorlin, C.-J. Chung, D. Nordlund, B. M. Clemens and T. F. Jaramillo, ACS Catal., 2012, 2, 2687-2694.

64 T. Rhadfi, J.-Y. Piquemal, L. Sicard, F. Herbst, E. Briot, M. Benedetti and A. Atlamsani, Appl. Catal., A, 2010, 386, 132-139.

65 X. Han, T. Zhang, J. Du, F. Cheng and J. Chen, Chem. Sci., 2013, 4, 368-376. 